\title{
Recursos literários e historicidade em Casa Grande \& Senzala de Gilberto Freyre Literacidade no equilíbrio de antagonismos
}

\section{Resumo:}

Publicado no Brasil em 1 de dezembro de 1933 com 768 páginas em sua primeira edição, Casa-Grande \& Senzala teve uma recepção bastante refratária no Brasil: inaugurava-se o regionalismo no campo sócio-histórico cultural ou um tratado lírico histórico das relações do Brasil colônia?

Ao longo dessas décadas, da sua recepção aos seus primeiros revisionismos, o ponto comum nas observações da construção técnica da obra é: O caráter plástico/artístico do texto. As relações de gênero, geografia, poder, culinária, folclore sendo tomadas não como puras descrições catalográficas e sim o desembrear da memória, que tem cor, cheiro e temperatura. Uma memória não apenas coletiva, mas também do próprio Freyre, que não queria apenas compartilhar opiniões, queria compartilhar experiências.

Palavras-chave: Gilberto Freyre, literacidade, história, identitade cultural, nação, regionalismo

\footnotetext{
Abstract:

Literary Resources and Historicity in Casa Grande \& Senzala from Gilberto Freyre. Literacy in the Balance of Antagonisms

Published in Brazil on December 1, 1933, with 768 pages in its first edition, Casa-Grande \& Senzala had a very refractory reception in Brazil: the regionalism in
} 
the socio-historical cultural field was inaugurated or a historical lyrical treaty of the relations of colonial Brazil?

Throughout these decades, from its reception to its first revisionisms, the common point in the observations of the technical construction of the work is: the plastic/ artistic character of the text. The relations of gender, geography, power, cuisine, folklore are taken not as pure descriptions of the catalog but rather the memory of memory, which has color, smell and temperature. Not only a collective memory, but also Freyre himself, who did not just want to share opinions, he wanted to share experiences.

Keywords: Gilberto Freyre, literacy, history, cultural identity, nation, regionalism

O ano de publicação de Casa Grande e Senzala (1933) de Gilberto Freyre é um ano de agitações políticas transnacionais. $\mathrm{O}$ embate entre fascismo e antifascismo é intenso em todo o mundo, além da falência económica à escala mundial ocorrida em 1929, na presidência do Brasil temos Getúlio Vargas.

No movimento literário há uma transição entre o Modernismo e o Neo-realismo. A partir de 1930 até 1945 os escritores retomam as críticas e as denúncias sociais aos grandes problemas do Brasil. Críticas marcadamente marxistas e o uso da ficção em decorrência dos regimes ditatoriais vigentes, as intenções eram mascaradas e o intimismo freudiano se destacava.

Casa-Grande \& Senzala, ampliação da dissertação apresentada em 1922 na Universidade de Columbia nos Estados Unidos. A obra se divide, formalmente, em cinco capítulos: o primeiro traça em linhas gerais os argumentos centrais que serão desenvolvidos mais acuradamente ao longo dos outros capítulos. O segundo trabalha o indígena na formação do Brasil, o terceiro mostra como os portugueses contribuíram com a nação e os dois últimos trazem o negro como ator fundamental na constituição do país.

Entre esses elementos, o da raça é extremamente relevante, sendo uma das principais contribuições do autor, a positivação da mestiçagem: "a mestiçagem, vista como origem de nossos males, transforma-se em nossa maior virtude" (Kominsky [et al.], 2003: 10). Freyre se insere nessa corrente de pensamento de interpretação do Brasil 
e veremos a seguir como Freyre refuta as teorias raciais de negativação da mestiçagem. "O modernismo rompe com este estado de coisas. As nossas deficiências, supostas ou reais são reinterpretadas como superioridades " (Candido, 1980: 143).

Ao tratar do palitar dos dentes dos senhores, ou dos banhos tomados com negras em sua infância, Freyre antecipa diversos temas que a Micro-História ou a História Cultural viriam décadas mais tarde apresentar, além de através da sua narrativa introduzir elementos geográficos em sua produção textual, fato que até então era creditado aos então grandes deuses da produção histórica, Os Annales franceses, é que se utilizavam desta metodologia que mudou a trajetória da escrita da História a partir do século XX.

Esses sujeitos e objetos, observados por um homem que do engenho foi para a América, dão a tônica da novidade freyriana, daí a sua importância, por que mesmo havendo alguns autores discordando ferozmente do livro, de fato ele inaugura uma discussão racial diferente. Além de tratar de costumes, culinária, hábitos e geografia, sempre na busca do que seria brasileiro, no conceito identitário e formador da nação. Além disto esta obra suscitou a descoberta de novos temas e novas discussões por parte dos intelectuais, seja pernambucanos, seja brasileiros. Segundo Vilhena:

Congregar intelectuais de todas as regiões do país para definir a identidade nacional, este é o objetivo do movimento folclórico, pretendendo expressarem sua organização igualmente a mesma visão de nação que ele constrói em seus estudos. A referência de Laytano ao "milagre" da nossa unidade territorial nos faz lembrar Gilberto Freyre e suas teorias sobre a originalidade da colonização portuguesa. Buscando as origens das concepções que nortearam o movimento folclórico, encontramos aqui um ponto que converge com interpretações que procuraram associar as perspectivas do movimento folclórico à visão de mundo patriarcal e agrária do escritor pernambucano (Baptista, 1985).

Não há dúvida que a obra de Freyre - que causou inicialmente um grande impacto mesmo sobre intelectuais que, mais tarde, ficarão associados a um tipo de ciência social responsável pelo declínio de seu prestígio 
(A.C. Mello e Souza, 1983: 42) - foi uma influência forte sobre os participantes do movimento folclórico e sobre a produção folclorística criada após seus primeiros trabalhos. [...] é necessário compreendermos esse impacto e voltarmos rapidamente aos debates anteriores à emergência da obra de Freyre, de maneira a mostrar sua influência sobre os folcloristas, menos literal do que boa parte da pequena bibliografia que examina o movimento folclórico e seus representantes supôs (Baptista, 1985: 3; Ortiz, 1988: 162).

Os objetos de análise aos quais Freyre recorre para traçar da vida íntima e da moral sexual no Brasil dos tempos da escravidão são bastante inusitados e inovadores para o momento: receitas de bolo, livros de modinha, livros de etiqueta, romances brasileiros, livros de viagem, cartas de jesuítas e mesmo iconografia (de imagens dos viajantes a pinturas a óleo).

O interesse dos analistas de Freyre não se esgota nos conteúdos de sua obra, mas também a forma de escrita, "o tom ensaístico, a vocação plástica e pictórica da descrição, o uso de recursos literários na expressão e o acento memorialístico, quase confessional, de parte de seus escritos" (Kominsky [et al.], 2003). Este tom ensaístico da obra de Freyre levou à sua classificação como trabalho não científico, o que de certa forma pode ser lido como não moderno, já que a ciência é moderna ${ }^{1}$ (Candido, 1980).

O método e a metodologia nos quais Freyre recorre estão intimamente ligados com a análise empreendida: ao buscar as filigranas da vida da família patriarcal - desenhando uma sociologia do cotidiano pautada em documentos inusitados - Freyre olha para um lugar específico: o interior das casas-grandes, e não as relações estabelecidas no eito. Para Skidmore (Skidmore, 2003), "a argumentação não-sistemática que por vezes não explicita de onde vêm algumas de suas teses" (por exemplo, os portugueses eram mais adequados que outros europeus para colonizar os trópicos) permite alinhar Gilberto Freyre não à ciência, mas à literatura. Skidmore explica que o motivo de Freyre

${ }^{1}$ Candido mostra que nesse período emerge a ciência no Brasil, a qual disputa com a literatura. 
optar pela última, está relacionado à pretensão de que sua obra fosse lida por um público amplo.

Não podemos deixar de destacar que a forma como um texto é escrito, construído e apresentado diz muito sobre o texto, seu autor, suas ideias. Assim, a forma (e essa palavra está repetida diversas vezes nessa argumentação) contribui de maneira decisiva para o texto e, desse modo, não pode ficar de lado em qualquer análise que se pretenda reflexiva ou crítica. Sendo assim, o que agora pretendo fazer é esboçar uma análise sobre a forma empregada por Freyre na construção de seu argumento. Ao invés de ressaltar as questões relacionadas à economia, as navegações, à imigração, e lhes dar uma centralidade nas explicações, Freyre prefere desenvolver outro tipo de argumentação.

Primeiro, o discurso inclina-se para a preocupação com um tom musical, arquitetônico e têxtil. Não são poucos os exemplos em que manifesta sua preocupação com a expressão literária de seus argumentos ou descrições, como por exemplo:

A verdade é que no Brasil, ao contrário do que se observa em outros países da América e da África de recente colonização européia, a cultura primitiva - tanto ameríndia como a africana - não se vem isolando em bolões duros, secos, indigestos, inassimiláveis; ao sistema social do europeu. (...) Suavizou-as aqui o óleo lúbrico da profunda miscigenação, quer a livre e danada, quer a regular e cristã sob a bênção dos padres e pelo incitamento da Igreja e do Estado. (Freyre, 2006: 231)

A citação acima contém em si uma parte da mediação que permeia todo o texto: A miscigenação. Que aparece como o elemento que medeia as relações e permite um equilíbrio no campo teórico e também social.

Em segundo lugar acredito que essa mediação, se é que ela existe, está mais relacionada à forma dada ao argumento do que apenas ao seu conteúdo. Isto é, a mediação ocorre por meio da categoria conceitual de Equilibrio de Antagonismos. Essa é a noção que percorre transversalmente todo o livro e que incorpora praticamente todo o argumento do autor. 
Desde o início do texto, Freyre deixa clara a sua tese principal sobre a particularidade do país.

No Brasil, as relações entre brancos e as raças de cor foram desde a primeira metade do século XVI condicionadas, de um lado pelo sistema de produção econômica - a monocultura latifundiária; do outro, pela escassez de mulheres brancas, entre os colonizadores. (Freyre, 2006: 32)

Nesse trecho, e ao longo da obra, fica claro que o sistema de produção econômica, a monocultura latifundiária, foi responsável pelo distanciamento operante no Brasil, entre as raças, entre as culturas, entre os senhores e as mulheres e crianças, entre a economia agrária e pastoril, entre o jesuíta e o fazendeiro, entre o grande proprietário e o pária e, especialmente, entre o senhor e o escravo.

Se no trecho acima, encadeado como um parafraseado de frases extraídas de um mesmo fragmento do prefácio parece antagônico, ele também está equilibrado. Trata-se da forma empregada por Freyre, forma que medeia as relações descritas no texto. A mulher indígena, o menino curumim, a escrava negra, são todas figuras que expressam o papel de mediação entre a cultura dominante e a cultura dominada, são os pontos porosos pelos quais a distância é diminuída e acentuada, em que a violência ocorre de forma desmesurada, mas potencializa a possibilidade de contato e relação.

É no cotidiano que essas relações são possíveis. Freyre, ao longo de sua obra, opera com categorias do cotidiano, com descrições do cotidiano, nesse sentido a forma aproxima-se, em certa medida, da a descrição de José Lins do Rego em "Menino de Engenho", pois em ambos os textos o cotidiano está presente. Seja tratando das relações sexuais, das relações com os animais, com as cores, com as comidas, com a igreja e os padres, com os jogos, folclores... enfim, é na descrição porosa do cotidiano que Freyre constrói seus argumentos e desenvolve a sua categoria de equilíbrio de antagonismos, que é tão convincente porque justamente não está separada em um capítulo específico, mas ramificada em diversos trechos, por vezes expressa em palavras claras e por vezes oculta em torno de um lirismo narrativo. 
Aqui faz-se necessário ir aos escritos de Benzquen de Araújo, justamente porque é o autor que permitiu mudar o olhar crítico que se lançava a Gilberto Freyre e que faz lançar a atenção para esse equilíbrio antagônico. Benzaquen faz esforço para relativizar as duas críticas, já citadas anteriormente. A segunda crítica já foi relativizada mais acima, agora resta relativizar a primeira ${ }^{2}$. Um ponto interessante é que nessa miscigenação entre os povos na península ibérica, as propriedades singulares de cada um desses povos não se dissolveu, mas sim cromatizou-se, de modo que o mestiço é justamente aquele que guarda a indelével lembrança das diferenças presentes em cada gestação de geração. Isso permitiu Gilberto Freyre definir o português, e mais tarde o brasileiro, em função de um "luxo de antagonismos" que, embora equilibrados, recusam-se a se desfazer e a se reunir em uma entidade separada, assim levando à uma sociedade híbrida, sincrética e polifônica.

Portugal só teria tido sucesso em sua expansão ultramarina devido à ilimitada mobilidade, miscibilidade e aclimantabilidade de sua população. Essas três características do português são condensadas na ideia de plasticidade, conceito este que representa a concretização da experiência étnica e cultural de Portugal. Assim, aqui verifica-se a critica sofrida por Freyre, pois a noção de miscigenação e a plasticidade reforça a visão idílica da colonização portuguesa no Brasil, em que parece estar descartada a violência e o conflito.

O que Benzaquen defende é que essa crítica atinge apenas parcialmente o seu alvo, e por isso deve ser debatida e qualificada. Para isso passa a pensar como a violência convive com essa plasticidade e com o suposto paraíso da experiência colonial. Como recurso de análise toma como referência duas tradições de lidar com a escravidão:

${ }^{2}$ A crítica seria de que o autor teria criado uma imagem quase idílica da nossa sociedade colonial, ocultando a exploração, os conflitos e a discriminação que a escravidão necessariamente implica atrás de uma fantasiosa "democracia racial", na qual senhores e escravos se confraternizam embalados por um clima de extrema intimidade e mútua cooperação. Para Benzaquem essa crítica não é inteiramente desprovida de fundamento o que o leva a acreditar que ela pode conduzir a algumas questões importantes. 
a clássica e a cristã. Se na tradição clássica a violência confunde-se com o despotismo e este permanece totalmente confinado à fronteira do lar, parece, à primeira vista que é justamente isso que ocorre na Casa-Grande - como se o gosto despótico e o terror impregnassem todas as relações íntimas - contudo, Freyre não está tratando somente dessa dimensão despótica, mas da heterogeneidade que cada relação despótica cria, não deixando de salientar a contribuição ativa que casa grupo antagônico possui na montagem da sociedade (verificamos aqui, mais uma vez o equilíbrio); além disso a noção de patriarcalismo, como categoria que nos remete a uma família extensa, sugere a convivência, na família, sob a égide de um ambiguidade de intimidade e violência, de disponibilidade e confraternização.

$\mathrm{Na}$ tradição cristã, por sua vez, a escravidão seria encarada como o fruto do pecado, mas há uma separação entre escravidão e despotismo (devido à concepção monogênica que acompanha a doutrina cristã, em que todos são considerados filhos de Adão), desse modo o escravo não está tão distante, ele é encarado, pelo contrário, como a criança que deve ser incorporada à casa do senhor.

Benzaquen oferece uma observação ambígua sobre o texto de Freyre: é possível perceber uma concepção de despotismo - comparável a noção da antiguidade clássica -, mas paralelamente há uma noção de intimidade, característica da tradição cristã, em que o escravo está incluído à casa-grande. Portanto, com Freyre, está-se diante de uma reflexão que combina o fragmento de duas tradições em um equilíbrio, orientando a leitura para uma visão do relacionamento entre grupos sociais que estão opostos, mas são plasticamente contornados. Assim, tal como o português que é plástico e resultado de influências étnicas e culturais distintas, no Brasil o despotismo e a confraternização familiar convivem em um amálgama tenso, mas equilibrado. Um amálgama que é descrito no dia-a-dia, que é narrado de maneira porosa e que compõe o ponto central da descrição de Freyre. Desse modo, a crítica baseada na ideia de que a imagem desenvolvida pelo autor sobre o Brasil seria meramente idílica pode ser repensada, não descartada, mas sim reelaborada e contextualizada, também, em uma chave histórica. 
Resta indagar se o equilíbrio proposto por Freyre pode ser rompido. A hipótese de Benzaquen é de que o excesso está sempre presente na obra, porque o trópico, o meio ao qual o Brasil está imerso, implicaria o excesso, e nesse ponto ele emprega a noção de hybris grega para falar do excesso de natureza sexual presente no Brasil. Segundo Benzaquen, é o excesso de natureza sexual que pode ser apontado como o maior responsável pela atmosfera de intimidade e calor que, sem descartar o despotismo, caracterizava as relações entre senhores e escravos na descrição de Freyre. Essa pulsão sexual que caracteriza o português faria predominar nas relações a irracionalidade e o furor típicos da paixão, convertendo a casa-grande e a sua família patriarcal em um cenário de rivalidades e desejos. Isso não quer dizer que não houvesse prudência e disciplina nas descrições do livro, e nos excessos existentes; ou mesmo que esses excessos sexuais não viessem acompanhados de vermes, doenças e portanto da morte. Contudo, o excesso sexual teria sido o principal responsável pela constituição das zonas de confraternização que contrabalanceavam o despotismo da escravidão e permitiam o equilíbrio nas relações. O que parece para Benzaquem é que esse excesso tanto rebaixava tanto redimia a vida social, a violência e o despotismo, do mesmo modo que gerava a intimidade e a confraternização. Assim, o modelo fica supostamente equilibrado, e não é possível vislumbrar o seu rompimento, pois "o domínio do excesso também vai permitir que a afirmação daqueles antagonismos seja perfeitamente compatível com um grau quase inusitado de proximidade, recobrindo de um colorido, de um ethos particular a senhorial experiência da casa-grande" (Araújo, 1994: 73).

Isso posto, é possível perceber, sob a tutela metodológica Benzaquen e com a leitura feita aqui, que Gilberto Freyre desenvolve um texto cuja forma e conteúdo se intercalam de maneira plástica. Não se trata de um argumento cartesiano, lógico, mas sim de uma narrativa em amálgama, na qual os conceitos não estão definidos de maneira explícita, mas sim imersos em um cotidiano perene. A categoria de Equilibro de Antagonismos permite a observação de uma relação que aproxima e distancia, mas que não deixa de ser uma relação fundadora no país que surgia. 


\section{Referências bibliográficas}

ARAÚJO, R. B. de (1994), Guerra e paz: Casa-Grande \& Senzala e a obra de Gilberto Freyre nos anos 30, Editora 34, Rio de Janeiro.

CANDIDO, A. (1980), Literatura e sociedade, Companhia Editora Nacional, São Paulo.

FREYRE, G. (2006), Casa Grande \& Senzala, Global, São Paulo.

KOMINSKY, E., LÉPINE, C., PEIXOTO, F. (orgs.) (2003), Gilberto Freyre Em Quatro Tempos, Edusp, Bauru.

PALLARES-BURKE, M. L. G. (2005), Gilberto Freyre. Um vitoriano nos trópicos, Editora UNESP, São Paulo.

SKIDMORE, T. (2003), "Raízes de Gilberto Freyre" em: Kosminsky, E. [et al.] (orgs.), Gilberto Freyre em quatro tempos, EDUSC, Bauru.

VILHENA, L. R., "Os intelectuais regionais", [on-line] http://www.anpocs. org.br/portal/publicacoes/rbcs_00_32/rbcs32_08.htm - 3.04.2018. 